- Review article

Plant Tissue Cult. \& Biotech. 26(2): 267-284, 2016 (December)

$\overline{\text { PTC\&B }}$

\title{
Genetic Imprinting: Comparative Analysis Between Plants and Mammals
}

\section{Oluwaseun Ogunwuyi ${ }^{1}$, Ankur Upadhyay, Simeon K. Adesina ${ }^{1}$, Reema Puri ${ }^{1}$, Tasha M. Foreman, Belinda R. Hauser ${ }^{2}$, Juanita Cox, Eric Afoakwah, Andre Porter, Emma Annan, Cheu Manka, Denloye Olatilewa, Bethtrice Thompson, Peter R. Kibanyi, Kimberly Miller and Hemayet Ullah*}

Department of Biology, Howard University, 415 College St., NW, Washington, DC 20059, USA

\begin{abstract}
Genetic imprinting: the parent of origin-specific biased expression of alleles is an important type of epigenetic gene regulation in flowering plants and mammals. All imprinted genes show either maternal - or paternal-specific mono-allelic expression. Considering that plants and mammals shared a common ancestor more than one billion years ago, significant overlap and potentially equally significant differences in the genomic imprinting mechanisms in these two taxa are emerging. In plants, the imprinted genes are primarily imprinted in the ephemeral endosperm tissues of the seeds which do not contribute any genome to future generations, while in mammals, the imprinted genes are located in embryo, placenta, and the adult body. Though both kingdoms silence imprinted genes using DNA methylation, imprinted alleles in mammals are targeted for silencing while in plants preexisting methylation is specifically removed from the allele destined to be active in maternally expressed genes in the endosperm. It is now accepted that imprinting evolved in both taxa due to competition between parental genomes over resource allocation to offspring. Moreover, the distinct life cycle stages between the taxa may account for the different strategies used by plants and mammals to regulate parent-specific gene expression. The elucidation of the genetic basis and molecular mechanisms responsible for genetic imprinting have provided answers to various crucial questions arising in biological sciences.
\end{abstract}

*Author for correspondence: <hullah@howard.edu>. ${ }^{1}$ Department of Pharmaceutical Sciences, College of Pharmacy, Howard University. ${ }^{2}$ Department of Microbiology, Howard Medical School, Howard University, USA. 


\section{Introduction}

Every autosomal gene that we inherit contains two copies, one from father and one from mother. Normally both of these copies are functional in most of our genes, but in some cases, one copy is turned off in a parent in an origindependent manner, which we call 'imprinted' genes. Most inherited autosomal genes in diploid organisms are expressed, without any parent of origin consideration, from the maternal and paternal copies (allele), thereby contributing equally to the phenotype (Li and Sasaki 2011). However, depending on the parent of origin, either the maternal or paternal allele of a gene is "turned off or on" within germline tissues - this biased expression of alleles without any genetic sequence differences is popularly known as genetic imprinting (GI) regulated gene expression. All imprinted genes show either maternal or paternal specific mono-allelic expression- meaning that the other allele remains silenced. Considering that plants and mammals shared a common ancestor more than 1 billion years ago (Meyerowitz 2002), significant overlap and potentially equally significant differences in the genomic imprinting mechanisms in these two taxa are emerging. In an attempt to elucidate the imprinting process from a biological perspective, this review will discuss these similarities and differences. More specifically, this review will seek to understand the basic differences in imprinting mechanisms; in mammals, imprinting 'marks' are erased and reestablished in each generation (Reik and Walter 2001), whereas in plants the preexisting imprinted 'marks' are removed from the allele destined to be active (Scott and Spielman 2006). This apparent dichotomy of GI mechanisms - selective inactivation in mammals and selective activation in plants at imprinted genes - is a key question that has been addressed in many research programs (Scott and Spielman 2006). Our current understandings of the topic in terms of their mechanism and function are not yet complete, but with the advent of genome analysis tools, a clear picture is emerging regarding this important, yet undervalued, biological phenomenon. A clear mechanistic understanding of GI in terms of both mechanistic and functional aspect will help readers appreciate the role of the GI in important biological pathways, including its implications for specific human diseases and reproductive growth and development in plants.

\section{Background}

Both the plant and animal kingdoms reflect parent-of-origin effects. It is well known that when a male horse is crossed with a donkey, the offspring is a hinny while an offspring is a mule when the horse is the female parent. In corn, certain alleles of the $R$ and $B$ genes produce fully colored kernels when inherited from one parent but not when inherited from the other parent. For many diploid 
genes, if the copy inherited from one parent is defective, there is a substitute allele from the other parent. However, in imprinting, even though there are two copies of the gene, it is as if there is a haploid gene, which makes imprinted genes more susceptible to the negative effects of mutations. Also, genes or mutations that are normally recessive can be expressed if a gene is imprinted and the dominant allele is silenced. It can be inferred that imprinting is quite different from the classical principles of Mendel because despite the equal distribution of parental autosomal genetic content to the offspring, the two alleles are differentially expressed. Imprinting is therefore a process whereby the expression of a genetic allele in a particular generation depends on whether the gene resides in the male or female in the previous generation. Fig. 1 presents the schematic diagram explaining the concept of genomic imprinting using a hypothetical example (Fig. 1B). The figure legend explains that in genomic imprinting, the maternal and paternal alleles of a particular gene are differently regulated.

In parallel, evidence for a global impact on seed development was gathered by crosses with different ploidy levels. Interploidy crosses in Arabidopsis affect endosperm development more than embryo development (Scott et al. 1998). Seeds from crosses of a diploid mother plant with a tetraploid father contain an over-proliferated endosperm with an increased number of nuclei (Fig. 2). By contrast, seeds from the reciprocal cross contain endosperm with fewer nuclei (Scott et al. 1998). Thus, an overdose of paternally derived genes (paternal excess) enhances growth, whereas an overdose of maternally derived genes (maternal excess) restricts growth, supporting the conflict hypothesis (Haig 2004). The conflict hypothesis proposes that selection will drive mono-allelic expression of paternally derived alleles that increase maternal resource allocation to the offspring (growth enhancers), while growth inhibitors are predicted to be expressed from the maternally-derived allele only. Experimental support for the parental conflict theory for imprinting evolution is largely derived from observations of expected overgrowth or undergrowth phenotypes when imprinted loci are disrupted in mammals (e.g. GNASxl, Grb10, IGF2, Igf2R) or in plants e.g. (MEDEA) (Dechiara et al. 1991, Grossniklaus et al. 1998).

In addition to the parental conflict theory which explains the evolution of imprinting, other theories which have been postulated include theories based on intra-locus sexual conflict, prevention of parthenogenesis, meiotic recombination, expression variance minimization, maternal-offspring co-adaptation, dosage compensation and selection for parental similarity (Reik and Dean 2001, Reik et al. 2003). Amongst these theories, the meiotic recombination-based and ovarian time-bomb theories have been supported with some experimental 


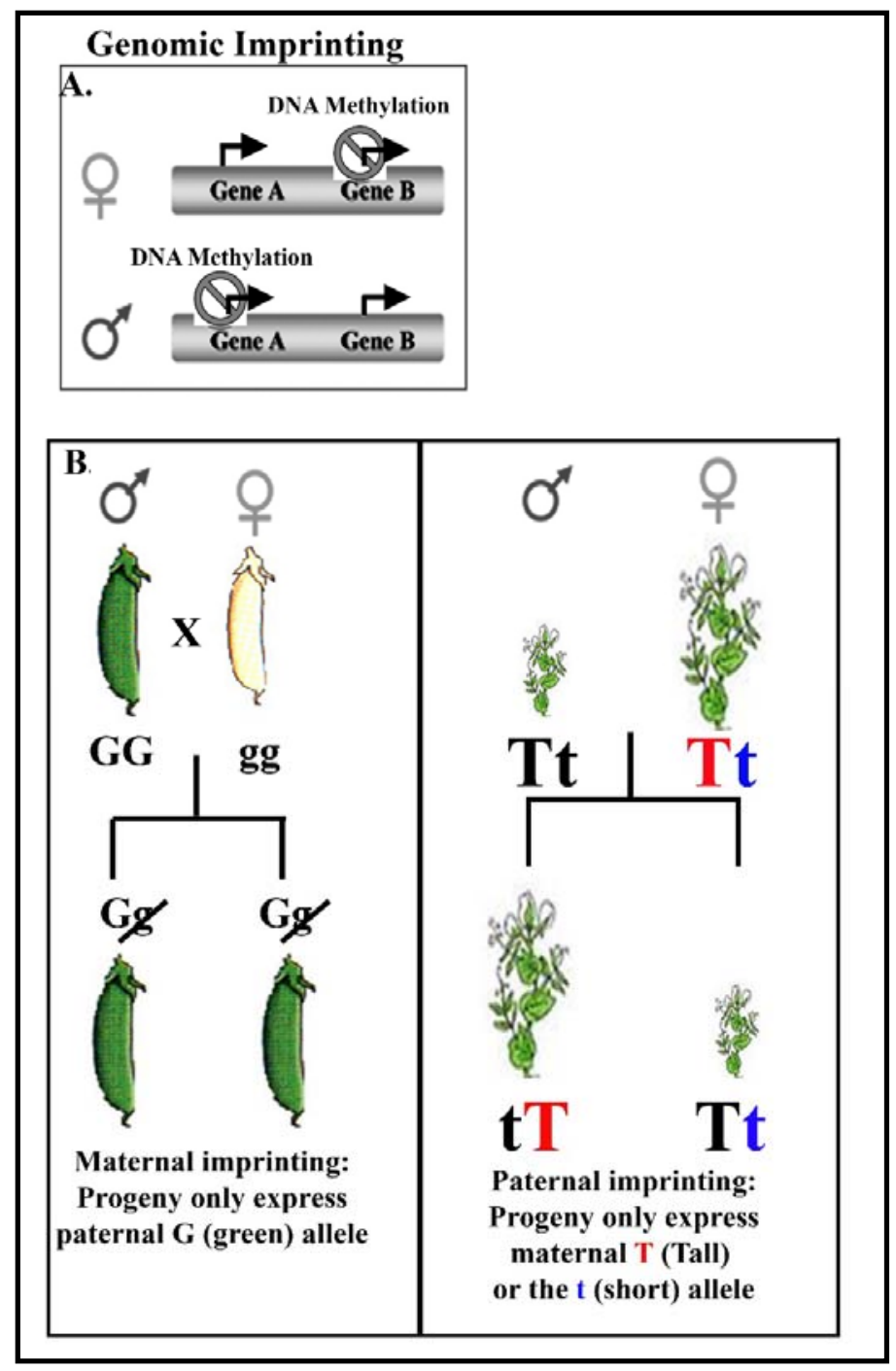

Fig. 1. Genomic imprinting concept. A. Organisms receive two copies of a gene - a paternal allele and a maternal allele. In genomic imprinting, the maternal and paternal alleles of a particular gene are differently regulated. Only one allele will be active in the embryo, so you need inputs from maternal and paternal genomes. The silencing of the maternal allele of Gene B or the paternal allele of Gene A is often the result of adding methyl groups to the cytosine or adenine bases on the regulatory regions of DNA, so that they cannot be transcribed into mRNA. Therefore, no protein is made. B. A hypothetical example to elucidate the effect of imprinting. Though, in plants, imprinting of alleles occur generally in the seed endosperm; for simplicity somatic tissue specific example is presented. In the left panel, maternal imprinting causes only the paternal allele to express in the progeny. In the right panel, paternal imprinting causes only maternal allele to express in the progeny. Note that even the heterozygous dominant stage is not showing tall plant when the $\mathrm{T}$ allele is inherited from the paternal genome. Essentially the locus is behaving as hemizygous (only one allele present as many alleles in $\mathrm{X}$ chromosome; no counterpart on the $\mathrm{Y}$ chromosome). 
evidence. It was proposed that there is a mechanistic link between the processes of genomic imprinting and meiotic recombination (Pardo et al. 2000). The ovarian time-bomb theory for the evolution of imprinting proposes that imprinting has evolved to prevent parthenogenesis (Solter et al. 1988). Support for this theory is derived from the failure of diploid gynogenetic or androgenetic embryos to develop to term (McGrath and Solter 1984)

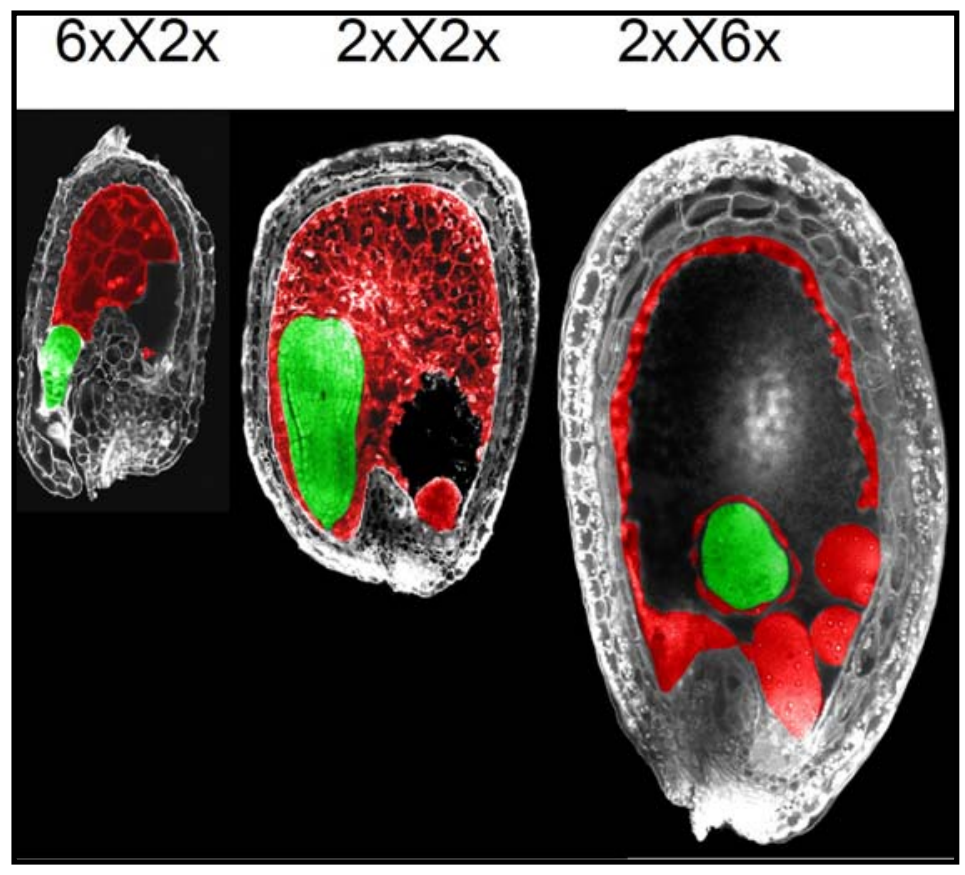

Fig. 2. Imprinting evolved in both plants and mammals due to competition between parental genomes over resource allocation. In plants, the maternalised endosperms with excess maternal genomes are small and paternalised endosperms are large. Confocal micrographs of Feulgenstained Arabidopsis seeds from interploidy crosses showing reciprocal developmental effects caused by parental genomic excess. The seed on the left was produced by a $2 x \times 6 x$ cross (paternal excess) while the seed on the right was produced by a $6 x \times 2 x$ cross (maternal excess). (Printed with kind permission of R.J. Scott).

\section{Generalized mechanism of genomic imprinting}

Genomic imprinting is thought to arise from DNA methylation mechanisms important for silencing foreign DNAs such as retrotransposons and other transposable elements and proviral DNA (Falls et al. 1999, Suzuki et al. 2007, Barjami and Spiroski 2016). Substantial evidence shows that DNA methylation plays a key role in imprinting in mammals and flowering plants (Scott and Spielman 2006), however, other epigenetic mechanisms such as histone methylation and complexes comprising Polycomb group proteins have also been 
reported to be involved in imprinting (Feil and Berger 2007). Since both parental chromosomes are present in a diploid somatic nucleus, the transcriptional apparatus of the cell is able to identify which of the two parental chromosomes should be expressed or repressed because of the presence of distinguishing, parent-specific epigenetic marks called "imprint stamp" or "parent-of-origin mark" on their controlling or regulatory regions (Reik and Walter 2001, RuggGunn et al. 2007, Barjami and Spiroski 2016). Depending on the kingdom, usually three events are essential for genetic imprinting: setting of the imprints in the germ line or epigenetic marking of alleles in the gametes, maintenance of the mark through cell division, that is, memory of the parental origin in the somatic line and response to the mark resulting uniparental gene expression after fertilization (Scott and Spielman 2006, Feil and Kelsey 1997). The nature of the imprint is epigenetic resulting in modification to the structure of DNA rather than a mutation in which DNA sequence is affected. Furthermore, the "imprint stamp" must be erasable in the germline when transmitted through individuals of the opposite sex but maintained during somatic cell division (Falls et al. 1999, Pfeifer et al. 2000).

\section{Genetic imprinting in plants}

In flowering plants, reproduction occurs by double fertilization whereby one of the two sperm cells fertilizes the binucleate central cell to generate the triploid endosperm which nourishes the plant embryo, while the fusion of the other sperm cell with the egg cell forms the zygote. Evidence shows that mono-allelic expression occurs only in the endosperm, affecting endosperm development and seed size, but there seems to be no mono-allelic expression at all in the embryo (Scott and Spielman 2006). In flowering plants, genetic imprinting has been demonstrated for a monocotyledon (maize) and a dicotyledon (Arabidopsis) (Baroux et al. 2002b). Because gymnosperms are devoid of a triploid endosperm, it was assumed that genetic imprinting does not occur in them (Btaroux et al. 2002b). Some of the imprinted genes that have been identified in maize (Zea mays) and in Arabidopsis thaliana include MEDEA, FWA, PHE1 FIS2, fie1 and fie2, Meg1, Nrp , Peg1 and Mez1 (Wilkins 2008).

\section{Examples of imprinted genes in plants}

$M E A$ is the first imprinted gene which was discovered in Arabidopsis. It is also the first imprinted locus discovered in plants with a role in regulating seed development (Grossniklaus et al. 1998). MEA is expressed from the maternal allele only within the endosperm, but bi-allelically in the embryo and various vegetative tissues, including the seedling, leaf, stem and root (Kinoshita et al. 
1999). As a maternally expressed, paternally silenced gene, according to the parental conflict model, MEA is predicted to encode an inhibitor of endosperm proliferation (Scott and Spielman 2006). The transcription factor FWA was found to be maternally expressed and paternally silent in Arabidopsis endosperm (Kinoshita et al. 2004). Its role in seed development, however, is not well understood (Scott and Spielman 2006). In addition, FWA is not normally expressed outside the seed (Soppe et al. 2000, Kinoshita et al. 2004). PHE1 is another imprinted gene that resides in Arabidopsis (Kohler et al. 2005). Importantly, PHE1 is preferentially expressed from the paternal allele, and so is the first paternal gene identified in this species (Scott and Spielman 2006). A function of PHE1 is suggested by the observation that expressing a PHE1 antisense transcript under control of the MEA promoter rescues a proportion of MEA mutant seeds, but the rescued seeds are larger than normal (Scott and Spielman 2006). From this finding it can be inferred that down-regulation of PHE1 attenuates the over-proliferation associated with the mea mutation, and in turn that the normal function of PHE1 is to promote seed growth. This is consistent with the prediction of parental conflict for a paternally expressed gene (Scott and Spielman 2006).

\section{Mechanism of imprinting in plants}

Similar to data from mammals, there is substantial evidence that DNA methylation plays a key role in imprinting in flowering plants (Scott and Spielman 2006). However, plants are capable of methylating a wider range of target sequences than mammals ( $\mathrm{CpG}, \mathrm{CpNpG}$ and asymmetric DNA sequences) and possess multiple de novo and maintenance DNA methyl-transferase genes (Chan et al. 2005). They appear to generate all imprinting-associated methylation via a single enzyme, MET1 (Kinoshita et al. 2004). The role of MET1 in imprinting was established using Arabidopsis plants carrying an antisense MET1 gene $(M E T 1 a / s)$ expressed under the near-constitutive $35 S$ promoter, which reduced global DNA methylation levels to approximately $13 \%$ of the wild-type level (Finnegan et al. 1996). Although MET1 is clearly a principal component of the plant imprinting mechanism, other genes are presumably required to bring about gene silencing. As shown in Fig. 3, within the female gametophyte, a haploid egg cell (Yellow) and a diploid central cell (green) are fertilized by two genetically identical haploid sperm separately resulting in a triploid endosperm with two maternal (MM) and one paternal (P) allele and a diploid embryo (MP), respectively. Many imprinted genes such as FIS2, FWA, MPC, remain silenced throughout the plant life cycle through MET1 activity. During male gametogenesis, silencing marks on these genes are maintained in the sperm cells; 
two steps of removal of methylation marks in the central cell of the embryo sac cause selective activation of these genes in the central cell (Fig. 3). In the first step, Retinoblastoma related $(\mathrm{Rb})$ interacts with Multicopysuppressor of IRA1 (MSI1) to repress MET1 causing hemi-methylated DNA (due to 'loss' of MET1 activity- DNA methylation is not maintained) represented as purple mark on the DNA (Fig. 3). In the next step, Demeter - a DNA glycosylase (DME) in the central cells - accepts its preferred substrate, hemi-methylated DNA, to remove methylated cytosines and produces two alleles of the genes completely free from any imprinted marks (Fig. 3). After fertilization of the central cell with the imprinted allele from the sperm produces the triploid endosperm (MMP) with maternal copies active while the paternal copy as inactive. Within the egg cell, lack of DME coupled with active de novo methylation by the Domains Rearranged Methylase (DRM1) gene restores imprinting on the egg cell genes, which is then fertilized by haploid sperm with imprinted genes, thus resulting in an embryo with no parent of origin mark identification (Fig. 3).

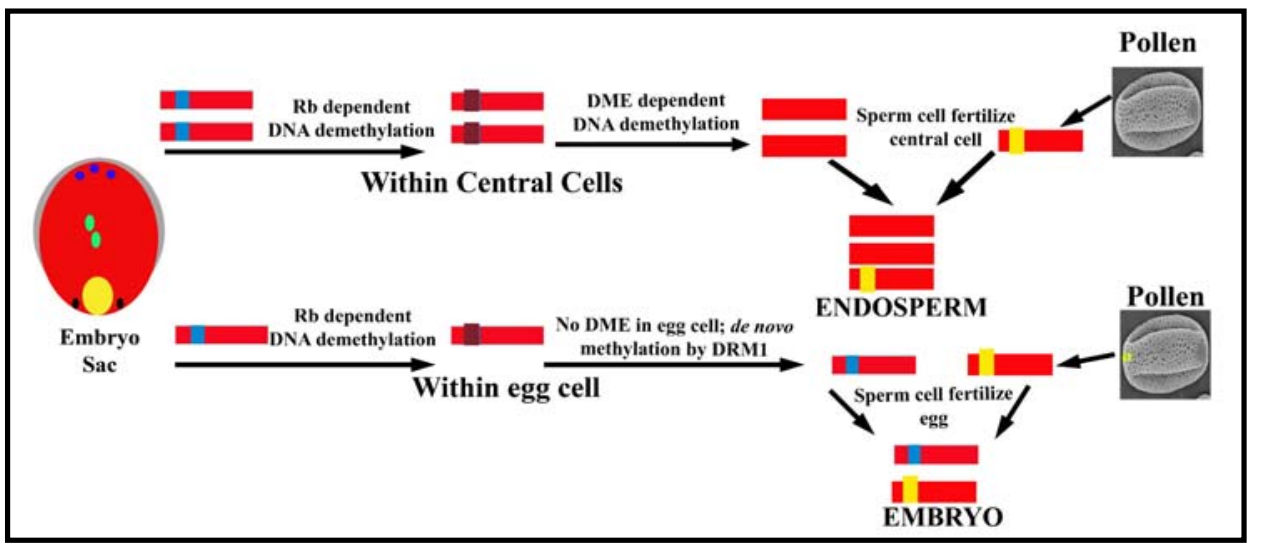

Fig. 3. Plant genomic imprinting: Within the female gametophyte, a haploid egg cell (Yellow) and a diploid central cell (green) is fertilized by two genetically identical haploid sperm separately. The endosperm is triploid and embryo is diploid. MET1 is repressed causing passive demethylation of central cell imprinted genes followed by active demethylation by DME - resulting in fully demethylated haploid central cell gametes which are fertilized by the methylated haploid sperm with methylated marks on the imprinted genes (active MET1 in sperm) resulting in the endosperm with one methylated inactive allele from sperm and two active demethylated alleles from the central cell (Within central cells arrows). Demethylated gametes are shown as without any colored boxes. Within the egg cell (Lower arrows), though passive demethylation happens on the imprinted genes (shown as small blue box in the red gamete turned to small purple box), lack of DME in egg cells coupled with active methylation by DRM1 restore imprinting on the egg cell genes which is fertilized by haploid sperm with imprinted genes - resulting in embryo with no parent of origin mark identification. Within the somatic cells, MET1 maintains methylation on both maternal and paternal alleles which are usually imprinted within the seed endosperm based on the parent of origin specific manner. 


\section{Genetic imprinting in mammals}

The elegant nuclear transplantation experiments pioneered by Solter and Surani in the 1980s were the first to suggest that the mammalian genome harbored imprinted genes (Surani et al. 1986). These experiments demonstrated that mammalian development requires genetic information from both parents, because diploid androgenetic embryos derived from two sperm pronuclei or diploid gynogenetic embryos derived from two female pronuclei fail to thrive. They reasoned that there must be genes that are exclusively expressed from one parental genome, and the failure of the uniparental embryos to develop appropriately was due to loss-of -function of such genes (Bartolomei and Tilghman 1997). The mouse genome contains about 150 imprinted genes (Plasschaert and Bartolomei 2014). Many features of genomic imprinting in mammals make it a fascinating biological problem in postgenomic times. It is intriguing that the subset of genes subject to genomic imprinting largely code for factors regulating embryonic and neonatal growth. Thus, it is likely that genomic imprinting evolved to play a specific role in mammalian reproduction.

\section{Mechanism of imprinting in mammals}

A large number of imprinted genes have been identified in mammals enabling relatively robust generalizations about the nature of the imprinting mechanism (Scott and Spielman 2006). Parental imprinting requires epigenetic marking of alleles in the gametes, maintenance of the mark through cell division, and response to the mark resulting in uniparental gene expression after fertilization (Scott and Spielman 2006). Cytosine methylation at CpG sequences provides one of these marks, and differential expression of mammalian imprinted genes is usually associated with parent-specific methylation of their regulatory regions (Reik and Walter 2001). The major maintenance DNA methyltransferase is Dnmt1 (Li et al. 1993). Dnmt1 faithfully copies patterns of cytosine methylation with CpG dinucleotides from parental to daughter DNA strand during DNA replication (Meehan 2003). However, there is evidence that this enzyme also has de novo DNA methyltransferase activity (Fatemi et al. 2000). Methylationassociated gene silencing is achieved either by blocking access of transcription factors to DNA, or through the recruitment of methyl-CpG binding domain (MBD) proteins, which form complexes with histone deacetylases, histone methyltransferases or chromatin-remodeling proteins to generate transcriptionally refractory chromatin ( $\mathrm{Li}$ 2002). However, based on the fact that there is a mechanistic link between DNA hypermethylation, histone deacetylation, and transcriptional repression predominate among mammalian imprinted genes, DNA methylation is not exclusively associated with silencing; for example the 
paternal allele of Insulin-like growth factor type 2 (Igf2) is expressed by virtue of methylation within an adjacent imprinting control region which prevents binding of the enhancer-blocking zinc-finger protein CCCCTC binding factor (CTCF) (Bell and Felsenfeld 2000). In other cases, DNA methylation may not be required for imprinting: $\mathrm{X}$-inactivation in mouse employs the non-coding Xist RNA, which 'coats' the inactivating $X$ chromosome, and is thought to bring about transcriptional silencing of $\mathrm{X}$-linked genes by attracting several histonemodifying enzymes including histone deacetylases and the Polycomb Repressive Complex PRC2 (Reik and Lewis 2005).

Fig. 4 schematically shows that the whole mechanism of genetic imprinting in mammalian lineage is confined to a cycle of establishment of imprints in gametes; maintenance of such imprints in the somatic cell lineages throughout the adult animal body and erasure of such marks in the germline lineages. As shown in the Fig. 4, imprints are acquired by the gametes; thus, egg and sperm already carry imprinted chromosomes (first-generation imprints). Here in the sperm, Gene $B$ is imprinted but not Gene $A$; whereas in the egg, Gene $A$ is imprinted but not gene $B$. After fertilization when the zygote is diploid, the imprint is maintained on the same parental chromosome after each cell division in cells of the embryo, yolk sac, placenta, and also in the adult. The germ cells are formed in the embryonic gonad and the imprints are erased only in these cells before sex determination. As the embryo develops into a male, the gonads differentiate to testes that produce haploid sperm that acquire a paternal imprint on their chromosomes. Similarly, in developing females, chromosomes in the ovaries acquire maternal imprints (second-generation imprints).

There are a few important characteristics of imprinted genes in mammals. Firstly, imprinted genes are usually in close proximity in the genome. For example, clusters of imprinted genes can be found at the distal position in chromosome 7 in mouse (Mancini-DiNardo et al. 2003). Other features include asynchronous DNA replication, temporal and spatial regulation of genomic imprinting (Bartolomei and Tilghman 1997).

\section{A comparison of the process of imprinting in plants and mammals}

There are many differences between the life histories of flowering plants and mammals that could account for differences in their imprinting mechanisms (Scott and Spielman 2006). Table 1 summarizes the key differences of genetic imprinting in plants and mammals. 


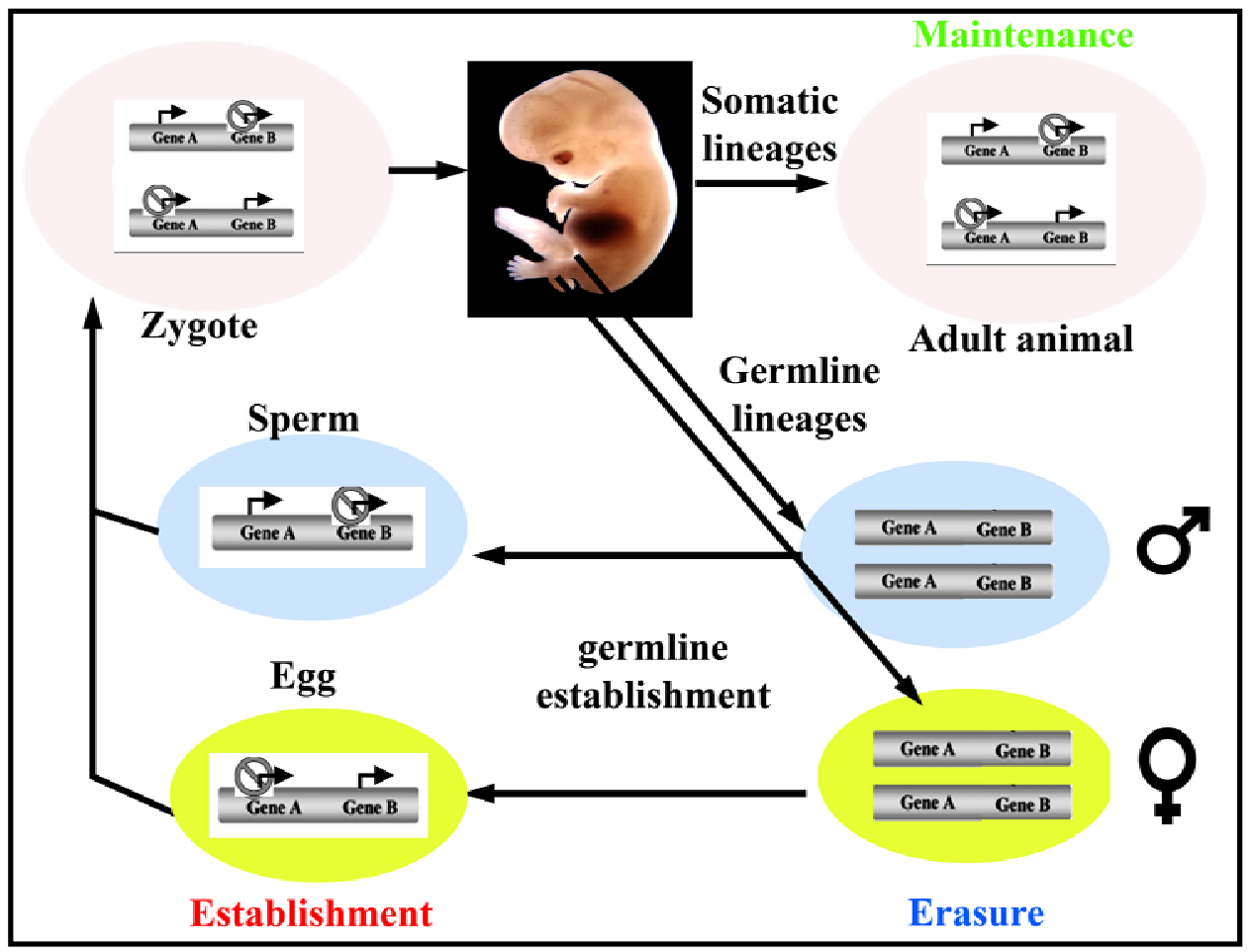

Fig. 4. Establishment, maintenance and erasure of genomic imprints in animals. In the somatic cell lineages, the genetic imprints mainly as DNA methylation at key control regions is maintained as present in the zygote. Here the Gene $A$ and Gene $B$ maintains the parent of origin specific imprints in the adult somatic cells. Because of the imprinting, the gene is expressed predominantly from one parental allele. In the germline lineage, the epigenetic marks are erased and reset in the nascent germline of each developing embryo. Thus, depending on whether an individual is a boy or girl, the marking that controls imprinted-gene expression is reset in the developing eggs and sperm, respectively. Here in sperm, the Gene $B$ is reset with imprints while in the egg, Gene $A$ is reset with imprints. After fertilization, the zygote maintains the reset imprints. Note that the maternally expressed Gene $B$ allele (non-imprinted) in the male individual will become imprinted in that male's offspring, as it will now be inherited as a paternal allele.

In mammals, the germline is set aside early in embryogenesis. A wave of global demethylation erases imprints, which are reset during gametogenesis according to the gender of the new individual in a process requiring de novo methyltransferases. The meiotic products differentiate directly into sperm or eggs. Propagation of the imprints then requires maintenance methyltransferase activity (Scott and Spielman 2006). The majority of imprinted genes affect growth of offspring in the direction predicted by the parental conflict hypothesis (Scott and Spielman 2006).

In plants, there is no separate germline; instead, the cells whose descendants will produce gametes are selected late in development, during differentiation of 
the floral organs. As most angiosperms species are hermaphrodite, imprinting is applied according to the gender of the floral organ rather than the individual (Scott and Spielman 2006). The meiotic products do not directly form gametes but instead give rise to multi-cellular, haploid gametophytes, which undergo several rounds of mitosis and produce not only gametes but accessory cells that participate in fertilization (Scott and Spielman 2006). Gametophytes in flowering plants are highly reduced and dependent on the surrounding sporophyte, but they are descended from free-living organisms that are still dominant life phase in lower plants, and express large numbers of genes. There is no evidence for global demethylation or resetting of imprints in plants. In addition, imprinting requires maintenance but not de novo methyltransferase activity. Imprinted gene expression occurs in the endosperm. Of the few imprinted genes discovered in plants, most also support the parental conflict hypothesis (Scott and Spielman 2006).

Table 1. Compare and contrast of genetic imprinting in plants and in mammals. Note that only the key characteristics of genetic imprinting are included but for elaborated comparison (see text).

\begin{tabular}{|c|c|c|}
\hline & Plants & Mammals \\
\hline Mechanism & $\begin{array}{l}\text { Mostly DNA methylation on } \\
\text { discrete genetic loci }\end{array}$ & $\begin{array}{l}\text { Mostly DNA } \\
\text { methylation, } \\
\text { X-inactivation, } \\
\text { mega deletion }\end{array}$ \\
\hline $\begin{array}{l}\text { Conform to parental conflict } \\
\text { hypothesis } \\
\text { (Resource allocation to offspring) }\end{array}$ & Yes & Yes \\
\hline Imprinted genes & $\begin{array}{l}\text { Selective activation by } \\
\text { demethylation }\end{array}$ & $\begin{array}{l}\text { Selective inactivation by } \\
\text { methylation }\end{array}$ \\
\hline Tissue location & $\begin{array}{l}\text { Only in the endosperm, rarely } \\
\text { in embryo (short lived) }\end{array}$ & $\begin{array}{l}\text { Embryo, placenta, and } \\
\text { adult tissues (long lived) }\end{array}$ \\
\hline Erasure of imprinting & $\begin{array}{l}\text { No erasure (true germline } \\
\text { absent); global loss of } \\
\text { methylation will compromise } \\
\text { plant development }\end{array}$ & $\begin{array}{l}\text { Global erasure (germline } \\
\text { present) }\end{array}$ \\
\hline Effect on embryo & No & Yes \\
\hline Number of imprinted genes & $\begin{array}{l}\text { Several dozen to hundred } \\
\text { (need confirmation) }\end{array}$ & Few hundreds \\
\hline Resetting of imprinting & $\begin{array}{l}\text { No resetting as imprinted genes } \\
\text { in endosperm do not pass on to } \\
\text { progeny }\end{array}$ & $\begin{array}{l}\text { Active resetting occurs } \\
\text { during primordial germ } \\
\text { cell development }\end{array}$ \\
\hline Partial imprinting & $\begin{array}{l}\text { Yes. Not 100\% mono-allelic } \\
\text { expression of imprinted genes }\end{array}$ & Yes \\
\hline Target sequences for methylation & $\begin{array}{l}\text { Wider range of target sequences } \\
\text { (CpG; CpNpG; and asymmetric } \\
\text { DNA sequences) }\end{array}$ & Narrower \\
\hline
\end{tabular}


In mammals, the de novo methyltransferases Dnmt $3 \mathrm{a}$ and $3 \mathrm{~b}$ are involved in resetting imprinting following global demethylation, while the maintenance methyltransferase Dnmt1 is required for maintaining methylation (Meehan 2003). Plants also possess bona fide de novo methyltransferase, Domain Rearranged Methyltransferase DRM1 and DRM2, but all evidences so far indicate they are involved to a lesser extent in plants (Kinoshita et al. 2004). In contrast, the Dnmt1 homologue DNA Methyltransferase 1 (MET1) is clearly an important part of the imprinting mechanism (Adams et al. 2000, Xiao et al. 2003, Kinoshita et al. 2004). Dnmt1 exists as a single gene in mouse but MET1 is one of a four-member gene family in Arabidopsis (Scott and Spielman 2006).

The spatial control of imprinting also appears to differ markedly in plants and mammals: in plants imprinted gene expression is largely or wholly restricted to the endosperm, the functional homologue of the mammalian placenta (Gehring et al. 2004). While in mammals, imprinted loci show allele-specific expression across many regions of the placenta and embryo (Hu et al. 1998). In addition while mammalian imprinted genes are found to be clustered in the fully sequenced human and mouse genomes (Verna et al. 2003). It is not possible at present to determine whether imprinted genes in plant genomes exhibit any significant clustering because of the small number of known imprinted genes in plants (Wilkins 2008).

\section{Future applications of genetic imprinting}

Flowering plants express genes depending on the parent of origin. However, this effect in plants appears to be limited to the endosperm. And the disruption in the imprinting machinery responsible for the selective expression of certain genes has led to embryonic lethality; affecting the endosperm development. However, it has been demonstrated using Arabidopsis thaliana, that imprinting can be bypassed subsequently producing uniparental (maternal origin) seeds which have a small size. As a result of the fact that a large proportion of food calories consumed all-over the world come from seeds (Kono et al. 2004), bypassing imprinting in certain plants can produce smaller sized seeds, which results in improvement in nutritional value as well as the quantity of agricultural produce (seed yield).

The effect of genetic imprinting spans several aspects of biological sciences and life. It has been proposed that the combination of genetics and epi-genetics can be employed in understanding the etiologies of some complex disorders which include autism, ADHD and schizophrenia. As opposed to the use of other traditional and slow methods of research in psychiatric genetics, which involves searching unknown genes in psychiatric phenotypes. 
Imprinted genes have also been implicated in controlling prenatal growth and regulating body weight in adults. Thus, it is also proposed that genetic imprinting can be linked to obesity of genetic origin. For example, the use of knock-out mice for imprinted genes, may provide more information about the function of genomic imprinting in regulating energy homeostasis (Lobo 2000).

The advent of high-throughput mRNA sequencing technologies is now allowing identifying imprinted genes in plants and in mammals through the use of allele specific gene expression (ASGE) assay (Babak et al. 2008). As explained in Fig. 5, in these studies, two strains with known polymorphisms are crossed, and allele-specific gene expression is assayed by mRNA sequencing in the resultant $F_{1}$ progeny. The technology has led to the discovery of a few hundred candidate imprinted genes in Arabidopsis and in other plants (Gehring et al. 2011, Hsieh et al. 2011, Zhang et al. 2011). As more ASGE information is gathered, it will be interesting to see if genes with close to $100 \%$ monoallelic expression are more likely to be imprinted in related species than are those genes that exhibit partial imprinting.

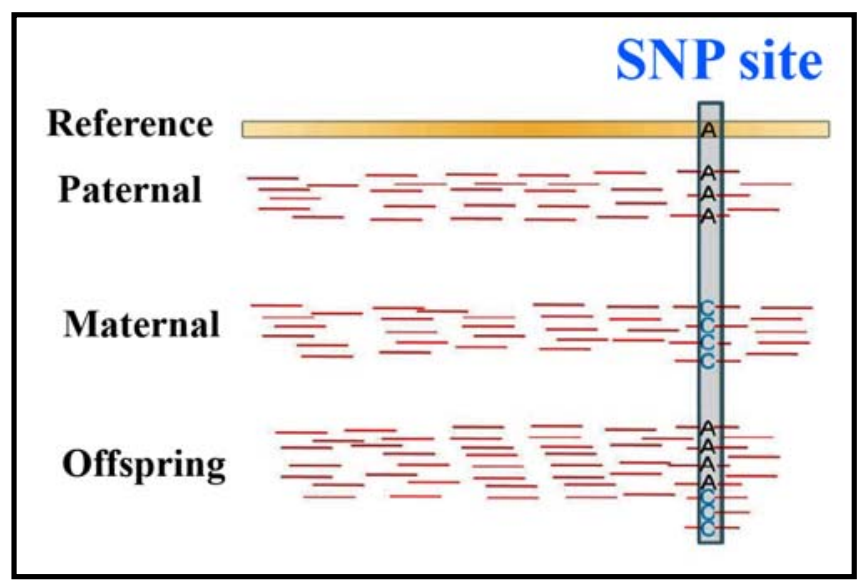

Fig. 5. Use of RNA-seq data to quantify allele specific gene expression (ASGE). The reference bar represents RNA-seq reads mapped to the reference transcriptome. Most reads from paternal origin match perfectly to the reference transcriptome. RNA-seq reads from maternal origin were also mapped to the reference transcriptome and SNPs sites were identified by comparing consensus bases of RNA-seq reads ( $\mathrm{C}$ in this case) to the corresponding base in the reference transcriptome (A in this case). In the offspring, reads mapped to SNPs sites are classified by the bases they carry and counted separately as the measurement of ASGE. In this SNP, 4 paternal allele reads and 3 maternal allele reads were counted in the offspring.

\section{Conclusion}

In conclusion, DNA methylation is involved in silencing alleles of imprinted genes in both flowering plants and mammals. The elucidation of the genetic basis and molecular mechanisms responsible for genetic imprinting has provided 
answers to various crucial questions arising in biological sciences. Although the number of imprinted genes in plants appears to be small in relation to mammalian imprinted genes, the recognition and description of novel imprinted genes and mechanisms in both taxa will provide a better understanding of imprinting in both mammals and plants. Though significant advances have been made in elucidating the imprinting mechanism, several questions, such as which forces select for imprinted expression, how are certain regions of the genome targeted for demethylation, and how do other forms of mono-allelic expression (e.g. long noncoding RNAs) relate to imprinting remain to be resolved.

\section{Acknowledgement}

This work culminates from a graduate molecular biology class exercise in the Department of Biology, Howard University, Washington, DC, USA. The authors greatly acknowledge the service of Dr. Janelle Burke, Biology Dept, Howard University for the critical readings of the manuscript. In addition, the authors also recognize the excellent editing service of Aniqa Tasnim of Harvard Medical School, Dept. of Neuroscience.

\section{References}

Adams S, Vinkenoog R, Spielman M, Dickinson HG and Scott RJ (2000) Parental imprinting in Arabidopsis requires DNA methylation. Development 127: 2493 -2502.

Babak T, Deveale B, Armour C, Raymond C, Cleary MA, van der Kooy D, Johnson JM and Lim LP (2008) Global survey of genomic imprinting by transcriptome sequencing. Curr. Biol. 18(22): 1735-41.

Bajrami E and Spiroski M (2016) Genomic imprinting; Maced. J. Med. Sci. 154(1): 181-4.

Baroux C, Spillance C and Grossniklaus U (2002b) Genomic imprinting during seed Development. Adv. Genet. 46: 165-214.

Bartolomei MS and Tilghman SM (1997) Genomic Imprinting in mammals. Annu. Rev. Genet. 31: 493-525.

Bell AC and Felsenfeld G (2000) Methylation of a CTCF-dependent boundary controls imprinted expression of the Igf2 gene. Nature 405: 482 -485.

Chan SW, Henderson IR and Jacobsen SE (2005) Gardening the genome: DNA methylation in Arabidopsis thaliana. Nat. Rev. Genet. 6: 351-360.

Dechiara TM, Robertson EJ and Efstratiadis A (1991) Parental imprinting of the mouse insulin-like growth factor II gene. Cell 64: 840-859.

Falls JG, Pulford DJ, Wylie AA and Jirtle RL (1999): Genomic Imprinting: Implications for Human Disease. Am. J. Pathol. 154(3): 635-647.

Fatemi M, Hermann A, Gowher H and Jeltsch A (2000) Dnmt3a and Dnmt1 functionally cooperate during de novo methylation of DNA. Eur. J. Biochem. 269: 4981-4984 
Feil R and Kelsey G (1997) Genomic imprinting: A chromatin connection. Am. J. Hum. Genet. 61(6): 1213-1219

Feil R and Berger F (2007) Convergent evolution of genomic imprinting in plants and mammals. Trends Genet 23(4): 193-199.

Finnegan EJ, Peacock WJ and Dennis ES (1996) Reduced DNA methylation in Arabidopsis thaliana results in abnormal plant development; Proc. Natl. Acad. Sci. USA. 93: 84498454.

Gehring M, Choi Y and Fischer RL (2004) Imprinting and seed development. Plant Cell 16: S203-S213.

Gehring M, Missirian V and Henikoff S (2011) Genomic analysis of parent-of-origin allelic expression in Arabidopsis thaliana seeds. PLoS ONE 6(8): e23687

Grossniklaus U, Vielle-Calzada JP, Hoeppner MA and Gagliano WB (1998) Maternal control of embryogenesis by MEDEA, a polycomb group gene in Arabidopsis. Science. 17: 280(5362): 446-50.

Haig D (2004) Genomic imprinting and kinship: how good is the evidence? Annu. Rev. Genet. 38: 553-585.

Hsieh T-F, Shin J, Uzawa R, Silva P and Cohen S et al. (2011) Regulation of imprinted gene expression in Arabidopsis endosperm. Proc. Natl. Acad. Sci. USA 108(5): 1755-62

Hu J-F, Orugantu H, Vu TH and Hoffman AR (1998) Tissue-specific imprinting of the mouse insulin-like growth factor II receptor gene correlates with differential allelespecific DNA methylation. Mol. Endocrinol. 12: 220-232

Kinoshita T, Yadegari R, Harada JJ, Goldberg RB and Fischer RL (1999) Imprinting of the MEDEA Polycomb gene in the Arabidopsis endosperm. Plant Cell 11: 1945-1952.

Kinoshita T, Miura A, Choi Y, Kinoshita Y, Cao X, Jacobsen SE, Fischer RL and Kakutani T (2004) One- way control of FWA imprinting in Arabidopsis endosperm by DNA methylation. Science 303: 521-523.

Kohler C, Page DR, Gagliardini V and Grossniklaus U (2005) The Arabidopsis thaliana MEDEA polycomb group protein controls expression of PHERES1 by parental imprinting. Nat. Genet. 37: 28-30.

Kono T, Obata Y, Wu Q et al. (2004) Birth of parthenogenetic mice that can develop to adulthood. Nature 428: 860-864

Li E (2002) Chromatin modification and epigenetic reprogramming in mammalian development. Nature Rev. Genet. 3: 662-673

Li Y and Sasaki H (2011) Genomic imprinting in mammals: its life cycle, molecular mechanisms and reprogramming. Cell Res. 21(3): 466-73.

Li E, Beard C and Jaenisch R (1993) Role for DNA methylation in genomic imprinting. Nature 366: 362-365.

Lobo I (2000) Genomic imprinting and patterns of disease inheritance. Nature Education $1(1)$.

Mancini-DiNardo D, Steele SJ, Ingram RS and Tilghman SM (2003) A differentially methylated region within the gene Kcnq1 functions as an imprinted promoter and silencer. Hum. Mol. Genet. 12(3): 283-94. 
McGrath J and Solter D (1984) Completion of mouse embryogenesis requires both the maternal and paternal genomes. Cell 37: 179-183.

Meehan RR (2003) DNA methylation in animal development. Sem. Cell Dev. Biol. 14: 53-65.

Meyerowitz EM (2002) Plants compared to animals: the broadest comparative study of development. Science 295: 1482-1485.

Pardo-Manuel de Veillena F, de la Casa-Esperon E and Sapienza C (2000) Natural selection and the function of genome imprinting: beyond the silenced minority. Trends Genet. 16: 573-579.

Pfeifer K (2000): Mechanisms of Genomic Imprinting. Am. J. Hum Genet. 67: 777-787.

Plasschaert RN and Bartolomei MS (2014) Genomic imprinting in development, growth, behavior and stem cells. Development. 141(9): 1805-13

Reik W and Dean W (2001) DNA methylation and mammalian epigenetics. Electrophoresis. 22(14): 2838-43.

Reik W, Santos F and Dean W (2003) Mammalian epigenomics: reprogramming the genome for development and therapy. Theriogenology 59(1): 21-32.

Reik W and Walter J (2001) Genomic Imprinting: Parental Influence on Genome. Nature Reviews Genetics 2: 21-32.

Reik W and Lewis A (2005) Co-evolution of X-chromosome inactivation and imprinting in mammals. Nat. Rev. Genet. 6: 403-410

Rugg-Gunn PJ, Ferguson-Smith AC and Pedersen RA (2007) Status of genomic imprinting in human embryonic stem cells as revealed by a large cohort of independently derived and maintained lines. Hum. Mol. Genet. 16 Spec No. 2: R243-51.

Scott RJ, Spielman M, Bailey J and Dickinson HG (1998) Parent-of-origin effects on seed development in Arabidopsis thaliana. Development. 125(17): 3329-41.

Scott RJ and Spielman M (2006) Genomic imprinting in plants and mammals: How life history constrains convergence. Cytogenet Genome Res. 113: 53-67.

Solter D (1988) Differential imprinting and expression of maternal and paternal genomes. Annu Rev Genet. 22: 127-146.

Soppe WJ, Jacobsen SE, Alonso-Blanco C, Jackson JP, Kakutani T, Koornneef M and Peeters AJ (2000) The late flowering phenotype of fwa mutants is caused by gain-offunction epigenetics alleles of a homeodomain gene. Mol. Cell 6: 791-802.

Surani MAH, Barton SC and Norris ML (1986) Nuclear transplantation in the mouse: heritable differences between parental genomes after activation of the embryonic genome. Cell 45: 127-136.

Suzuki S, Ono R, Narita T, Pask AJ, Shaw G, Wang C, Kohda T, Alsop AE, Marshall Graves JA, Kohara Y, Ishino F, Renfree MB and Kaneko-Ishino T (2007) Retrotransposon silencing by DNA methylation can drive mammalian genomic imprinting. PLoS Genet. 13; 3(4): e55.

Verna RI, Mann MR and Bartolomei MS (2003) Genomic imprinting: intricacies of epigenetic regulation in clusters. Annu. Rev. Cell Dev. Biol. 19: 237-259

Wilkins JF (2008) Genomic imprinting. Adv. Exp. Med. Biol. 626: ix-xii. 
Xiao W, Gehring M, Choi Y, Margossian L, Pu H, Harada JH, Goldberg RB, Pennel RI and Fischer RL (2003) Imprinting of MEA polycomb gene is controlled by antagonism between MET1 methyltransferase and DME glycosylase. Dev. Cell 5: 891901.

Zhang M, Zhao H, Xie S, Chen J, Xu Y et al. (2011) Extensive, clustered parental imprinting of proteincoding and noncoding RNAs in developing maize endosperm. Proc. Natl. Acad. Sci. USA 108(50): 20042-47. 